\title{
Strategies of Examination and School Evaluation Carried out in Brazil: Thinking about Power Relations and Discipline from the Foucaultian Perspective
}

\author{
Linsmar Nascimento Lenartovicz ${ }^{1}$, Aldo Sena de Oliveira ${ }^{1,2^{*}}$ \\ ${ }^{1}$ Postgraduate Program in Teaching Natural Sciences and Mathematics, University of Blumenau, Blumenau, Brazil \\ ${ }^{2}$ Department of Exact Sciences and Education, Blumenau Center, Federal University of Santa Catarina, Blumenau, Brazil \\ Email: *aldo.sena@ufsc.br
}

How to cite this paper: Lenartovicz, L. N., \& de Oliveira, A. S. (2018). Strategies of Examination and School Evaluation Carried out in Brazil: Thinking about Power Relations and Discipline from the Foucaultian Perspective. Creative Education, 9, 2791-2803.

https://doi.org/10.4236/ce.2018.916209

Received: November 13, 2018

Accepted: December 15, 2018

Published: December 18, 2018

Copyright $\odot 2018$ by authors and Scientific Research Publishing Inc. This work is licensed under the Creative Commons Attribution International License (CC BY 4.0).

http://creativecommons.org/licenses/by/4.0/

\begin{abstract}
In this article, we discuss strategies for school evaluation, emphasizing the types of evaluation that exist in Brazil. We discuss in this work the use of school exams, the valorization of the quantitative aspects in qualitative detriments in the evaluation processes and the use of the evaluations as instruments of disciplinary control. As a theoretical basis, we use the philosopher Michel Foucault, as the title suggests, from the Foucaultian perspective, to enable a more in-depth debate about the power relations that subsidize the teacher-student dialogue and that they denote in the elaboration of pedagogical practices. Finally, we discuss the incompatibilities of traditional models of school evaluation and contemporary society, characterized by the formation of numerous networks, discussing the urgent need to think about an educational practice, and its consequent evaluation, more in keeping with contemporary challenges.
\end{abstract}

\section{Keywords}

School Evaluation, Disciplinary Control, Power, Contemporaneity

\section{Introduction}

Evaluation is a stage of teaching and learning, much discussed since the birth of the first schools in the mid-seventeenth century. Its use in school spaces has permeated diverse strategies of power and, in many cases, has served the purpose of disciplinary control. This article aims to present some of the evaluative forms used in Brazil, in order to problematize the power relations imbricated by 
the error identification techniques, when of its execution and its use as a discipline maintenance strategy. The research is based mainly on the works of the philosopher Michael Foucault, although the philosopher did not take care of strictly to discuss this subject, but his propositions about the relations of power provide us theoretical subsidies to do it.

Regarding the origin of the evaluation process, the evaluation is a later invention, born with the colleges around the seventeenth century and made inseparable from the mass education that we have known since the nine-tenth century, with compulsory schooling (Perrenoud, 1999). Thus, the conception of evaluation that should be used as a criterion for verifying learning also has strong rootedness in the exam, with an exclusionary classification and selective use, thus constituting an instrument of power.

The educator has the power to qualify what an educator posesses, so he can determine what should or should not become conscious or unconscious and stop the process of growth for freedom, autonomy and the construction of knowledge (Luckesi, 1994).

Evaluating is neither measuring an object, observing a situation, nor uttering value judgments. It is pronouncing, that is, taking sides over the way in which expectations are realized, that is, on the measure in which a real situation corresponds to a desired situation. This implies that one knows what one must desire (to pronounce a judgment on the value, from that point of view, of what exists), and to observe the real (it will be necessary to collect observable) on the desired axis. Evaluation is a guided reading operation of reality (Hadji, 2001).

In this sense, the evaluation of learning is fundamental in the educational process, in which it is necessary to follow the appropriation of the themes and the construction of the student's knowledge. Therefore, it is necessary to use pedagogical tools intentionally designed to follow the paths of multiple learning. The evaluation of learning presents three basic functions: to diagnose (to investigate), to control (to follow) and to classify (to value) (Haydt, 2000). These functions are directly related to their modalities: diagnostic, formative and summative. Our evaluation practices are crossed by two logics that are not necessarily excluding: formative and summative (Perrenoud, 1999). This is related more to the product demonstrated by the student in situations previously stipulated and defined by the teacher, and materializes in the note, object of desire and suffering of students, their families and even the teacher himself. The bureaucratic bias that impoverishes learning predominates in this logic, stimulating didactic actions aimed at controlling the activities carried out by the student, but not necessarily generating knowledge (Perrenoud, 1999). In the following section we present some strategies of evaluation of learning, emphasizing the qualitative aspects.

\section{Qualitative Evaluation as a Learning Verification Strategy}

On qualitative evaluation, there are many criticisms about the models and prac- 
tices of evaluation in our schools. There is a rapid development of alternative evaluation approaches, with very different ethical, epistemological and theoretical assumptions (Chuieire, 2008).

With the increase in interest in evaluation methods and the search for more adequate information about students' appropriation of knowledge, there was an interest in inserting other qualitative aspects, in addition to quantitative aspects, in the elaboration of evaluation devices. This insertion was influenced by the epistemological movements against criticisms of the traditional method and the comprehension of the evaluation as something much more complex than the classic binarism involving approving or simple disapproval.

The qualitative evaluation intends to go beyond the quantitative evaluation, with-out dispensing with it. It understands that in the educational space the processes are more relevant than the products, not living up to reality, if reduced only to the empirically measurable manifestations. These are easier to manipulate methodologically, because the scientific tradition has always favored the measured treatment of reality, advancing sometimes incisively in some social disciplines such as economics and psychology. However, the methodological limitation cannot be transferred to the alleged reduction of the real. This is more complex and comprehensive than its empirical face. Qualitative evaluation would like to reach the qualitative aspect of reality, or at least approach it (Chuieire, 2008).

Traditionally associated with school, evaluation creates hierarchies of excellence. Students are compared and then classified by virtue of a standard of excellence, defined in absolute or incarnated by the teacher and the best students (Perrenoud, 1999). Besides the creation of hierarchies, certification is another function of evaluation, which serves as a proof of aptitude in the school context. A certification provides few details of the knowledge and skills acquired and the domain level precisely acquired in each field covered. It ensures, above all, that a student knows globally "what is necessary to know" to move to the next series in the course, to be admitted to a qualification or to start a profession. The advantage of an established certification is precisely that it does not need to be controlled step by step, as a passport to employment or for further training (Perrenoud, 1999).

The qualitative evaluation model is configured as a transition model to have as central the understanding of the subjects' processes and learning, which produces a rupture with the primacy of the characteristic result of the quantitative process (Esteban, 2003)

In this sense, that the qualitative evaluation tries to respond to the imposition of the qualitative evaluation to apprehend the dynamics and intensity of the learning-teaching relationship but articulated by principles that support the knowledge-regulation-market, state and community (Chuieire, 2008).

In the classroom and in the proposals that arrive at the school, the maintenance of the practice of evaluation based on the classification logic is exclusive, although the practice acquires an innovative appearance and that the concept of 
school evaluation associated with the quantification of the student's income is the object of many deep critiques. Over the years evaluative strategies have been acquiring different ways of being applied to learners, although the strategy of control, discipline and power on the part of the educator are evident clear in practically every stage (Esteban, 2001).

Based on the assumptions that support its elaboration, the evaluation can be understood according to the classifications: classificatory evaluation, summative evaluation, diagnostic evaluation, formative evaluation, mediator evaluation and dialogic evaluation, whose peculiarities will be presented below.

\section{Evaluation}

\subsection{Classificatory Evaluation}

It is linked to the idea of measurement, a mathematical judgment and an objective of quantifying school learning. The school performance standard is performed by comparing performance from pre-established standards by the teacher and then placed in a learning ranking. The notion of measure shows the existence of performance standards by comparing the performance of a student who will be evaluated and ranked.

The classification function, evaluation constitutes the static and slowing instrument of the growth process. This evaluative technique interferes with the self-esteem of the learner, since once the learner has been classified, the first learner will increase his/her fights for the first places, and the learner will have the less satisfactory result will have their self-esteem diminished, often not knowing what was taught them, but for the form of evaluation that was used, aiming only the classification and not the verification of the learning (Luckesi, 1986).

\subsection{The Summative Evaluation}

It is a process of final evaluation of an instructional program aimed at judging it, where the educator establishes a final concept adopting based on all stages of learning (Ferreira, 1999). At the end of the series or year, the summative evaluation verifies that the learner has met all the established objectives and has acquired the knowledge and skills, being classified by means of a document of level verification obtained. The summative evaluation is to classify the students at the end of the unit, semester or school year, according to levels of achievement presented. The summative evaluation therefore has a classificatory function at the end of the teaching process, with the aim of verifying if there was learning, and with the intention of classifying the student and is linked to approve or disapprove, with a clear measurement intentionality (Haydt, 2000).

\subsection{Diagnostic Evaluation}

According to different theorists, this evaluation acquires different interpretations. The diagnostic evaluation is a constant, formative process (Luckesi, 1986). 
This evaluation should occur at the beginning of each cycle of studies, since the time variable may favor or hinder subsequent trajectories, if a constant, critical and participatory reflection is not done, or an "initial evaluation," used as an anamnesis to identify what the learner already knows (Sant'Ana, 1995).

\subsection{Formative Evaluation}

Contrary to classifying evaluation formative evaluation, in which evaluation must be a permanent and daily process, not an occasional, extemporaneous, untimely, threatening intervention (Demo, 1996). The traditional model of individual and written proof is discarded as a relevant criterion of evaluation because it not only evaluates such a precarious and suspicious performance (memorization), but above all because it is not a natural component of the educational process. In both the teacher and the student, the test is seen as an act of strength, a hard barrier to be overcome, with a clear tendency to be exclusive. The result is typical: instead of strengthening the educational path, it grants or withdraws approval, not to mention that it is not a way of evaluating, in which the evaluator can adequately defend himself (Demo, 1996). The formative evaluation needs a multiple school commitment, because one can only move forward in this direction by changing the culture of the school organization, not only in the classroom but also in the establishment (Perrenoud, 1999).

\subsection{Mediator Evaluation}

The mediating evaluation considers that the maximum possible development happens when there is learning, understanding, questioning and participation of the learner. The first and essential meaning of mediating evaluative action is to pay close attention to children and young people, insisting on getting to know him better, understanding his speeches, his arguments, insisting on talking to him at all times, listening to all of them their questions, making them new and challenging "implicating" questions, even in the search for alternatives to an educational action focused on moral and intellectual autonomy (Hoffmann, 2000).

The understanding of critical dialogic evaluation the authoritarian and meritocratic posture of the teacher in leading the student to knowledge. The mnemonic character of working the teaching process forces the learner to become a deposit of knowledge without meaning for learning and for life (Romão, 1999). The evaluation is no longer a memorization, but a greater involvement of communication that benefits the moment of learning. The mediating conception of evaluation, the subjectivity inherent in the elaboration and correction of evaluative tasks is not a problem, but an element to work positively because, without taking the task as a terminal moment, but as a great current link, both the "Mistakes" of the students and the teachers' doubts in interpreting them, will return to the classroom to be discussed by all, important and positive elements in the continuity of actions developed, other proposed tasks. The moment of correc- 
tion becomes a moment of reflection on the hypotheses that have been constructed by the student and not to consider them as definitely right or wrong (Demo, 1996).

In short, the evaluation is something much more complex than just assigning notes about a test or test that is done; it must be embedded in the learner's learning process. They can be classified in:

1) Formative: aims to verify if everything that was proposed by the teacher in relation to the contents are being reached throughout the learning teaching process;

2) Cumulative: in this type of evaluation allows to retain everything that is learned during classes and the teacher can be accompanying the student day by day, and use when necessary;

3) Diagnostics: it helps the teacher to detect or to do a survey on what has been learned or not, and thus to resume the contents that the student has not been able to learn, preplanning their actions to meet the needs and reaching the proposed objectives;

4) Summative: aims to assign notes and concepts for the student to be promoted from one class to another, or from one course to another, usually during the two-month period;

5) Self-evaluation: it can be done by both the student and the teacher, to be aware of what has been learned or taught and thus improve learning. In group: it is the evaluation of the works that the students accomplished, where the activities, the income and the learning are verified.

From this analysis, the evaluation constitutes a reflexive moment about theory and practice in teaching-learning. When assessing, the teacher will be verifying the learning conditions of the students, and, from there, provide means for their recovery, not for their exclusion, if they consider the evaluation a process, not an end.

\section{The Power Announced in the Discourse of Truth and the Role of Evaluation as the Controlling Element of the Discipline: Foucaultian Looks}

Philosophically, the word power can be defined in a broad context as the ability to achieve something, whether by right, control or influence. Power is the ability to mobilize economic, social, or political forces to achieve a certain outcome (Blackburn, 1997). Foucault says that the established power relations, whether by control institutions, schools, prisons, barracks, were marked by discipline: but discipline brings with it a specific way of punishing, which is only a reduced model of the court (Foucault, 2008). It is by discipline that power relations become more readily observable, for it is through the discipline that situates relations: oppressor-oppressed, mandating-agent, persuasive-persuaded, and as many relationships as express command and command (Ferreirinha \& Raitz, 2010). 
It is not surprising that a significant number of teachers use evaluations as an element of threat and early coercion of students (Luckesi, 1995). In this sense, evaluation is, in many cases, a disciplinary strategy of learners, often used as a form of threat and coercion. The consequences of this type of evaluation, centered in the examination, are clearly expressed in the development of submissive personalities of the student, who often suffers the manifestation of the exacerbation of authoritarianism.

The practice of school evaluation, if used as a tool to control the discipline, loses its constitutive meaning. Because it is in the bosom of a pedagogy that reflects the aspirations of a narrowly conservative society, it exacerbates authority and oppresses the student, impeding their growth. From a dialectical instrument it becomes a disciplinary instrument of the individual history of each one's growth (Luckesi, 1995).

The relationship of power between the teacher and the student is complex, because in a class that is evaluated by test, the result is always seen as failure or individual success of the student. It is as if the pedagogical process was perfect and only the student guilty of misunderstanding their development (Pontes, 2001).

In this way the teacher is the holder of power, it is he who attributes the note and merit of the promotion to the following years. They are practices used in the school in "common" ways as a ritual that must be fulfilled without the student expressing his thought, because who is evaluated, coerced is him. Discipline first proceeds to the distribution of individuals in space (Foucault, 2008). However, spatial organization, schedules, hierarchical scale, all lead to these institutions the prescription of established and homogeneous human behaviors.

For this, Foucault sees in language a configuration already constituted in society, and for this reason, the discourses of truth are used for a long time by analyzing the discourses themselves, we see if they undo the apparently strong ties between words and things, and highlight a set of rules, proper to discursive practice (Foucault, 1985).

As for the exercise of the discipline, Foucault supposes a device that coils by the game of the look; an apparatus where the methodologies that allow to see induce the effects of power, and where, in exchange, the means of coercion make clearly those on whom they apply (Foucault, 2008). Foucault (Foucault, 2004) explains that the "truth speeches" of society, through their language, behavior and values, are relations constituted of power and, therefore, imprison the subjects. This disciplining power is inserted in the social context of control as "natural", "true", from these discourses and unquestionable, under the sanction of being excluded or punished socially by the institutions of control. Penalty, vigilance and control would then be a way of managing illegalities, of setting tolerance limits, of giving some ground to others, of putting pressure on others, of excluding one part, of making another useful, of neutralizing them, of take advantage of those (Foucault, 1987). 
Foucault, considers three premises in relation to the exam in the exercise power:

1) The exam reverses the economy of visibility in the exercise of power: Power is what is seen, shown and manifested. Its force is in the movement with which it is exhibited. Disciplinary power, on the contrary, is exercised with invisibility. In the discipline are the sub missives that must be observed. Examination is the technique by which power, instead of emitting the signs of its power, instead of imposing its mark upon its subjects, captures them in a mechanism of objectification (Foucault, 2008).

2) The examination also makes individuality enter a documentary field: The exam places the subjects under surveillance, where the written tests capture, classify and verify who has achieved the expected goal. Hence the formation of a series of codes of the disciplinary individuality that allow transcribing, homogenizing them; the individual traits established by the examination mark the moment of a first "formalization" of the individual within relations of power (Foucault, 2008).

3) The examination, surrounded by all its documentary techniques, makes everyone a case: The examination becomes the strategy that gives status to the subject, which quantifies or "measures" them through grades and classifications and thus be a case study. A case that at the same time constitutes an object for knowledge and an outlet for power (Foucault, 2008).

The activity that ensures learning and the acquisition of skills or types of behavior develops throughout a set of regulated communications (lessons, questions and answers, orders, exhortations, codified signs of obedience, differential marks of the "value" of each one and the levels of knowledge) and through a whole series of procedures of power (enclosure, vigilance, reward and punishment, pyramid hierarchy (Foucault, 2004).

Thus, Foucault (Foucault, 1987) states that discipline is gradually imposed on pedagogical practice, specializing the time of formation and highlighting it from adult time, the time of the acquired office; organizing various stages separated from each other by graded exams; determining programs, which must each take place during a certain stage, and which involve exercises of increasing difficulty; qualifying the individuals according to the way they went through these series. The school becomes an apparatus of learning where each student, each level and each moment, if combined in the correct way, are permanently used in the general teaching process (Foucault, 1987).

School evaluation is a complex process to determine the value of something, which implies a delicate task of interpreting a set of elements that interact to configure a and meaningful reality. In fact, evaluating is not strictly the later or final step of a process, but a moment in the path to appreciate the walk and decide how to continue. An evaluation is not characterized by the data, although these are indispensable, but by the process by which one appreciates and discovers the value of actions and achievements; a deeply human process that nourish- 
es itself and articulates itself in dialogue, discussion and reflection (Coneau. 1997).

\section{The Evaluation of Error and the Strategies of Disciplinary Control through the Examination: Thinking of the Relations of Power}

The meaning of error is misleading; incorrectness; mistake; lack; sin, suggesting the inability to achieve an expected response. Thus, the error only exists when a standard in advance is established, and the correctness is the only possibility admissible (Bueno, 1996). However, when students' mistakes are valued as essential in the educational process, the possibility of uncertainties and doubts must also be assumed (Hoffmann, 2001). Under this concept, the error is identified as an important step, since it allows the educator to rethink his practice and contributing to the improvement of this stage, seeking to guarantee the improvement of learning.

For Foucault (Foucault, 2003) the school becomes a kind of continuous examination apparatus that accompanies throughout its length the operation of teaching, perpetual comparison of each with all, which allows at the same time to measure and punish. Thus Foucault (Foucault, 1987) states that the examination, however, is not content to sanction an apprenticeship; is one of its permanent factors: it sustains it according to a constantly renewed ritual of power. In this context, the school is considered a cunning space, because it associates the disciplinary power within the various disciplinary strategies and in the construction of new discourses of truth and new knowledge.

The school becomes a place for the elaboration of pedagogy (Foucault, 1987). This comparison between individuals allows their objectification and the formation of groups on a scale of power-knowledge. For Foucault the examination is at the center of the processes that constitute the individual as effect and object of power, as effect and object of knowledge (Foucault, 1987).

Foucault sees in language a configuration already constituted in society, and for this reason, the discourses of truth are used for a long time: by analyzing the discourses themselves, we see if they undo the seemingly strong ties between words and things, and highlight a set of rules, proper to discursive practice (Foucault, 1985).

Foucault (Foucault, 2004) explains that the "truth speeches" of society, through their language, behavior and values, are relations constituted of power and, therefore, imprison the subjects. This disciplining power is inserted in the social context of control as "natural", "true", from these discourses and unquestionable, under the sanction of being excluded or punished socially by the institutions of control. Penalty, vigilance and control would then be a way of managing illegalities, of setting tolerance limits, of giving some ground to others, of putting pressure on others, of excluding one part, of making another useful, of neutralizing them, of take advantage of those (Foucault, 1987). 


\section{The Disciplinary Society and the Incompatibilities between the Evaluation Devices and the School in the Contemporary World}

The disciplinary society, being analyzed in a critical way, presents a crisis in the school institution (Deleuze, 1992). This crisis is related to an "incompatibility" between the school subject of today and the model of school institution present for a certain time: this incompatibility may be indicating the impact of the entrance of a new historical subject with other demands and values, in an archaic and unprepared order to absorb it fully (Aquino, 1996). With all this, the school has become a space explicitly removed from the issues that move people's lives and further away from the challenges of society (Mosé, 2013).

Despite the scientific euphoria of the eighteenth and nineteenth centuries, intensely influenced by freedom of thought, revolutionizing human and social relations, the school found itself anchored more in bureaucratic aspects of capitalism than in the idea of emancipation. There is a heavy inheritance for the school that has organized itself into a pyramidal structure, hierarchical and that made knowledge something to be assimilated, memorized, and not constituted, thought critically (Mosé, 2013).

Breaking up with exclusivist strategies, in particular, the result of the exam that quantifies and selects the good student and excludes the bad student, is a first step in valuing students and bringing them closer to the contemporary model, aiming at the development of educational aspects such as creativity, the capacity for abstraction, and the significance of what is taught to the student.

A school that values memory and repetition, that is, decoration, reminds us of what Paulo Freire called "banking education" 40 years ago. With the digital revolution, memory can be stored in the virtual world, leaving the learner with the possibility of freedom of thought, intelligence and creativity (Mosé, 2013). I would dare to say that the exclusion of knowledge, of knowledge, is the root of all exclusion. It is especially because of this that we need a new school (Mosé, 2013).

What we need to face is that either the school becomes a living space of production of knowledge, of valuing curiosity, of research, of art and culture, of creativity, of reflection, a space of ethical and democratic coexistence in which citizenship is practiced, a space linked to the community to which it belongs, as well as to the city, the country, the world, or it will become antiquated and will be doomed to disappear (Mosé, 2013).

\section{School Evaluation and Exclusion: Possible Relationships}

Generations of children and young people passed through a school that did not stimulate them to think about society, its historical constitution, its network of interests and conflicts, its contradictions. This lack of relationship with society has harmed, and still harms, not only the cognitive aspect of the students, but also the increase of the isolation and the affliction of the individuals (Mosé, 
2013).

The incompatibility of evaluation in contemporary school is one of the aspects to be raised, a possible attempt to adapt to the school for an evaluation of skills and abilities. "The Brazilian academic environment has been very resistant to this, considering that an evaluation of competences and skills values only a formation for the market, which I disagree (Mosé, 2013).

We live in network, connected to the internet, in the labor market, citing the capitalist question, we work in networks, large cooperatives, large corporations, network of schools, supermarket networks, network of universities. Perhaps we are in a moment to suggest a new way of network evaluation, in which the individual will have access to all means of access to information, but it will be up to the teacher to be able to formulate the questions with the capacity to abstract the questions from there either alone or in a network, try to solve the problem question proposed by the teacher. The one who knows how to research, who knows how to argue, who has a systemic view, who knows how to connect with the world, is a citizen of the moment in which he lives (Mosé, 2013). Now of the digital society, the information is put on the network. It is no longer the school that has the possession of the "socialization" of knowledge, nor is it the teacher who knows everything. If there is too much information, if all the knowledge is contained in books and the internet, it will be up to the school to redefine its place in the process of training children and young people. Instead of transmitting content and information, the school should teach its students to select and think critically (Mosé, 2013).

Instead of wondering about the future of school, we must ask ourselves about the future of education, and the future of education must be sought on the side of non-school education, where there are many experiences and much knowledge produced today (Mosé, 2013). There is an urgent need to rethink evaluation currently of transition. Society, in general, lives now a moment of profound transformations in the cultural, social and knowledge contexts. The school today deals with a multireference generation, which articulates simultaneous processing. In the same way, educational systems need to work in multiple and differentiated aspects, generating a demand for what the authors call new educations (Pretto \& Pinto, 2006). According to Vasconcellos (Vasconcellos, 2005) evaluation must lead to a change in what must be changed also at the level of the educational system, the change in the evaluative practice goes through the challenge of giving it a new intentionality. The need for the reconstruction of the evaluation process is necessary as part of a movement articulated by the commitment to the development of a pedagogical practice committed to inclusion, with plurality, with respect for differences, and collective construction (Esteban, 2001).

\section{Final Considerations}

The evaluation, the stage of teaching learning that should occur daily and as a verifier of the proposed educational objectives, occurs from its origin, in the exams in the first schools of the seventeenth century, without this connotation, 
presenting a selective, excluding, disciplinary and coercive role. In this article we have discussed some situations about the relationship of power and discipline with a Foucautian philosophical view.

Evaluative strategies are late and incompatible with contemporary society. The major part of evaluation modalities that are currently used in Brazil little or nothing have evolved into a truly effective strategy and achieve its real role in teaching learning. The methods used still focused only on the verification of the error, do not consider it as part of the learning, using the evaluation as excluding and disciplining role. In school there is a tensioning of discourses of truth where the role of the educator is highlighted in the possession of knowledge and power. The instrument of examination or evaluation is used as a controlling and social disciplining method. Contemporary society is undergoing great transformations, and the need to rethink the evaluation is urgent. We live in a network and the school is a metareferential simultaneous articulator of thoughts.

The limitations of this research are directly related to the lack of theoretical understanding of philosophical issues involving tensions in power relations between teachers and students, with greater methodological rigor.

Questions and assumptions about evaluation are beyond question, as well as controversial! Important authors such as the philosopher Foucault, Luckesi, Hoffmann, Perrenould and others provide extensive literature on evaluation, instigating new readings concerning the subject of this article.

\section{Conflicts of Interest}

The authors declare no conflicts of interest regarding the publication of this paper.

\section{References}

Aquino, J. G. (1996). The Disorder in the Teacher-Student Relationship: Indiscipline, Morality and Knowledge. A desordem na relação professor-aluno: Indisciplina, moralidade e conhecimento. Em Indisciplina escolar: Alternativas teóricas e práticas. São Paulo: Summus.

Blackburn, S. (1997). Oxford Dictionary of Philosophy. Rio de Janeiro: Jorge Zahar.

Bueno, F. S. (1996). Mini Dictionary of the Portuguese Language. São Paulo: FTD, LISA.

Chuieire, M. S. F. (2008). Conceptions about School Evaluation. Estudos em Avaliação Educacional, 19.

Coneau (1997). Lineamientos para la evaluación institucional. Buenos Aires.

Deleuze, G. (1992). Post-Scriptum about Control Societies (p. 34).

Demo, P. (1996). Evaluation under the Propaedeutic Eye. Logic and Democracy of Education. Qualitative Evaluation. Campinas: Papirus.

Esteban, M. T. (2001). Who Knows Who Is Wrong? Reflections on Evaluation and School Failure (3rd ed.). Rio de Janeiro: DP\&A.

Esteban, M. T. (2003). School, Curriculum and Evaluation. Série Cultura Memória e currículo (Vol. 5). São Paulo: Cortez.

Ferreirinha, I. M. N., \& Raitz, T. R. (2010). The Relations of Power in Michel Foucault: 
Theoretical Reflections. Revista de Administração Pública-RAP, 44.

Foucault, M. (1985). Words and Things: An Archeology of the Human Sciences. São Paulo: Martins Fontes.

Foucault, M. (1987). Discipline \& Punish: The Birth of the Prison (Trad., Raquel, R., 27th ed.). Petrópolis: Vozes.

Foucault, M. (2003). Dictations and Writings IV: Strategy, Power-Knowledge. Rio de Janeiro: Forense Universitária.

Foucault, M. (2004). Microphysics of Power (Trad., Roberto, M., 19th ed.). Rio de Janeiro: Graal.

Foucault, M. (2008). Watch and Punish: Birth of the Prison. Tradução de Raquel Ramalhete (35th, ed.). Petrópolis: Vozes.

Hadji, C. (2001). Demystified Evaluation. Porto Alegre: Artmed.

Haydt, R. C. (2000). Evaluation of the Teaching-Learning Process. São Paulo: Ática.

Hoffmann, J. (2000). Mediator Evaluation: A Practice in Construction from Pre-School to University (18th ed.). Porto Alegre: Mediação.

Hoffmann, J. M. L. (2001). Evaluation: Myth and Challenge: A Constructivist Perspective (30th ed.). Porto Alegre: Mediação.

Luckesi, C. C. (1986). Educational Evaluation. Revista Ande (Vol. 10). São Paulo: Cortez.

Luckesi, C. C. (1995). Evaluation of School Learning: Studies and Propositions. São Paulo: Cortez.

Luckesi, C. C. (1994). Philosophy of Education. São Paulo: Cortez.

Mosé, V. (2013). The School and the Contemporary Challenges (336 p). Rio de Janeiro: Editora Civilização Brasileira.

Perrenoud, P. (1999). Evaluation: From Excellence to Regulation of Learning-Between Two Logics. Porto Alegre: Artes Médicas Sul.

Pontes, T. S. (2001). Evaluation in Early Childhood Education, in Face of the New Challenges. Belém: Unama.

Pretto, N., \& Pinto, C. C. (2006). Technologies and New Education. Brazilian Journal of Education.

Romão, J. E. (1999). Dialogical Evaluation: Challenges and Perspectives. Avaliação dialógica: Desafios e perspectivas. São Paulo: Cortez, Instituto Paulo Freire.

Sant'Ana, I. M. (1995). Why Evaluate? How to Evaluate? Criteria and Instruments. Petrópolis: Vozes.

Vasconcellos, C. (2005). Evaluation: Dialectical Conception Liberating the Process of School Evaluation (15th ed.). São Paulo: Libertad. 